\title{
Study of endothelial function response to exercise training in hypertensive individuals (SEFRET): study protocol for a randomized controlled trial
}

Marinei Lopes Pedralli, ${ }^{1,2}$, Gustavo Waclawovsky ${ }^{1}$, Augusto Camacho ${ }^{1}$, Melissa Medeiros Markoski ${ }^{1}$, Iran Castro ${ }^{1}$ and Alexandre Machado Lehnen ${ }^{1,3^{*}}$

\begin{abstract}
Background: Endothelial dysfunction is a hallmark of diabetes mellitus and systemic arterial hypertension (SAH) and an early maker for atherosclerosis. Aerobic exercise training is known to enhance endothelial function, but little is understood about the effects of resistance or combined exercise training on endothelial function. The aim of this study is to investigate the effect of a 12-week aerobic (AT), resistance (RT), or combined (aerobic and resistance, CT) training program on endothelial function and assess associated effects on blood pressure in individuals with SAH.

Methods/design: Eighty-one subjects with SAH aged 18 to 70 years will be selected and randomly assigned to three types of exercise training: AT, RT or CT. The study will involve the following procedures and tests: anamnesis, anthropometric assessment, echocardiography, blood pressure measurements through ambulatory blood pressure monitoring, flow-mediated dilation, ergospirometry, one repetition maximum test (1-RM), and blood collection (number of circulating endothelial progenitor cells, number of circulating endothelial microparticles, lipid profile, glucose, glycated hemoglobin, and creatinine). The AT intervention will consist of a 40-min exercise session with progressive intensities ranging from 50 to $75 \%$ of heart rate reserve. The RT intervention will consist of a 40-minute session with four sets of six to 12 repetitions with a rest period of 60 to 90 seconds between each set and each type of exercise. Weight loads will be adjusted to 60 to $80 \%$ of 1-RM for six types of exercise. The CT intervention will consist of a 20-min aerobic exercise session, followed by an additional 20-min resistance exercise session; each resistance exercise will have two sets less to match the total training volume.

Discussion: The study results are expected evidence of cardiovascular protective effects of different types of exercise training through the modulation of endothelial function in hypertensive individuals. Knowing the magnitude of improvement of endothelium-dependent vasodilation for the different types of exercise training can provide scientific evidence for the prescription of exercise programs for vascular protection targeting hypertensive individuals.
\end{abstract}

Trial registration: The Brazilian Clinical Trials Registry (http://www.ensaiosclinicos.gov.br/) under RBR-9ygmdn and dated 1 March 2015.

Keywords: Endothelial function, Exercise training, Hypertension

\footnotetext{
* Correspondence: amlehnen@gmail.com

'Laboratório de Investigação Clínica, Instituto de Cardiologia / Fundação

Universitária de Cardiologia - ICFUC, Av. Princesa Isabel, 395. Bairro Santana,

90620001 Porto Alegre, RS, Brazil

${ }^{3}$ Faculdade Sogipa de Educação Física, Porto Alegre, Rio Grande do Sul, Brazil

Full list of author information is available at the end of the article
} 


\section{Background}

Cardiovascular diseases are largely determined by multifactorial risk factors that tend to interact and may be present over the course of an individual's lifetime. Obesity $[1,2]$, physical inactivity $[3,4]$, and insulin resistance [5] are all risk factors closely associated with systemic arterial hypertension (SAH) and diabetes mellitus type 2 . In addition to these risk factors, smoking [6] and excess weight [7] contribute to endothelial dysfunction [8, 9], which is a hallmark of diabetes mellitus [10] and SAH [11] and an early maker for atherosclerosis [12].

The endothelium is a single layer of cells that lines the tunica intima of blood vessels [13] and plays a major role in the modulation of vascular angiogenesis, inflammatory responses, and vascular tone and permeability [14]. Vascular protection is particularly attributable to endothelial nitric oxide synthase (eNOS), an enzyme involved in the production of nitric oxide (NO).

The balance between endothelial injury and recovery is critical to continuously maintaining endothelial function [15]. The bone marrow releases a progenitor cell subtype called endothelial progenitor cells (EPCs), which have the ability to migrate to the peripheral circulation and differentiate into mature endothelial cells to maintain vascular integrity [16]. EPC levels have been associated with cardiovascular risk factors [17], endotheliumdependent vasodilation [18], and clinical outcomes, including hospitalization and cardiovascular death rates [19]. In patients with cardiovascular risk factors such as SAH [20], smoking [21], metabolic syndrome [22] and diabetes mellitus [23], circulating levels of EPCs can be reduced compared with healthy individuals of matching age and sex. Endothelial dysfunction has been associated with a decreased number and impaired function of EPCs in patients with $\mathrm{SAH}$, diabetes mellitus, and metabolic syndrome, and thus an increased risk of atherosclerosis would be expected [24].

On the other hand, regular exercise, also known as exercise training, produces effects on the cardiovascular system and has been proven to restore endothelial function even in the presence of cardiovascular disease [25]. Regular exercise promotes changes in cholesterol levels and its subfractions; accelerates the removal of chylomicrons and low-density lipoproteins from circulation; increases the release of $\mathrm{NO}$ that seems to generate increased expression of eNOS [26]; increases the number of circulating EPCs in healthy individuals [27], as well as in individuals with established cardiovascular disease [28]; and improves plasma glucose [29], which has a direct link to impaired endothelial function [30]. This assumption is consistent with findings in healthy individuals [31], individuals with diabetes mellitus type 2 [32], and patients with cardiovascular conditions [33], showing that exercise training improved vascular function and overall health.
Evidence with clinical relevance exists on the impact of aerobic exercise on BP and blood glucose levels, but no consensus exists regarding the effects of resistance training and even less evidence is available on combined training (resistance and aerobic) and the regulatory mechanisms of endothelial function and its relationship with BP in hypertensive individuals. Thus, despite present evidence showing the benefits of exercise and physical training on blood pressure [34] and blood glucose levels [35], more studies are needed to investigate further the mechanisms involved with endothelial function especially their relationship with blood pressure reduction.

The objective of this study is to evaluate the chronic effects of exercise training on endothelial function modulation in hypertensive patients undergoing a 12week exercise intervention of aerobic, resistance, or combined (aerobic and resistance) training. Modulation of endothelial function will be assessed by flow-mediated dilation (FMD) [36] and biochemical [37] and cellular parameters [38, 39]. The primary and secondary study objectives are listed in Tables 1 and 2, respectively.

\section{Methods/design}

The study will be coordinated at the Fundação Universitária de Cardiologia (FUC) Health Sciences Graduate Program together with the Instituto de Cardiologia (IC) in the city of Porto Alegre, Rio Grande do Sul, Brazil.

\section{Study design}

A randomized controlled and evaluator-blinded clinical trial will be conducted as shown in Fig. 1.

\section{Sample selection}

The study sample will comprise individuals with no history of cardiovascular disease (except for SAH controlled with the use of medications), neuromuscular, endocrine, and/or metabolic conditions (except for diabetes mellitus type 2) who are attending the IC health care facilities.

Subjects will be selected based on information collected from their medical records. Eligible individuals will be contacted by telephone and informed of the purpose and procedures of the study. For those willing to participate, a first visit will be scheduled when a clinical questionnaire will be administered, and they will be asked to sign a free informed consent form to participate in the study. Other study visits will be scheduled for

Table 1 Primary objectives of the study

$$
\begin{aligned}
& \text { - To investigate the effects of AT, RT and CT on flow-mediated vasodilation } \\
& \text { of the brachial artery in hypertensive individuals } \\
& \text { - To assess the impact of different types of training (AT, RT, and CT) on the } \\
& \text { number of circulating endothelial progenitor cells and number of circulating } \\
& \text { endothelial microparticles in hypertensive individuals }
\end{aligned}
$$

AT, aerobic training; $R T$, resistance training; $C T$, concurrent training 
Table $\mathbf{2}$ Secondary objectives of the study

To assess the effectiveness of different types of training (AT, RT and CT) regarding the following:

- Blood pressure levels: clinical assessment and ABPM

- Serum levels of total cholesterol, HDL, LDL and triglycerides

- Fasting blood glucose and glycated hemoglobin

- Blood viscosity, RBC deformability, RBC aggregation, fibrinogen levels and ESR

- Echocardiography for determination of heart chamber sizes and wall thickness

- Functional capacity through maximum oxygen consumption $\left(\mathrm{VO}_{2} \mathrm{max}\right)$

$\cdot$ 1-RM

- Abdominal obesity and BMI

ABPM, ambulatory blood pressure monitoring; $A T$, aerobic training; RT, resistance training; $\mathrm{CT}$, concurrent training; $\mathrm{HDL}$, high-density cholesterol; $\mathrm{LDL}$, low-density cholesterol; RBC red blood cell; ESR, erythrocyte sedimentation rate; 1-RM, one-repetition maximum strength test; BMI, body mass index.

those meeting the inclusion criteria of the study (Table 3).

The following formula will be used for the calculation of sample size $\left(n_{p}\right)$ to estimate the number of hypertensive individuals to be included in the study:

$$
\left(\mu_{\mathrm{p}}\right): \mathrm{n}_{\mathrm{p} 0}=\mathrm{s}^{2} /\left(\mu_{\mathrm{p}}-\mathrm{x}_{\mathrm{p}}\right)^{2} \mathrm{x}\left(\mathrm{t}_{\alpha ; \mathrm{gl}}\right)^{2}
$$

where, $\mathrm{n}_{\mathrm{po}}=$ sample size at time point zero, $\mathrm{s}^{2}=$ variance of the sampling distribution, and $t_{\alpha ; g l}=$ sampling distribution according to a predetermined error probability $(P \leq 0.05)$ and degrees of freedom for $n_{\text {po }}$.

The mean incidence rate of SAH in Brazil is $20 \%$ of the population [40]. Considering the baseline value $\left(\mathrm{n}_{0}=30\right)$; $\mathrm{t}_{\alpha ; \mathrm{gl}}=\mathrm{t}_{0.05 ; 29}=2.045 ; \mathrm{s}^{2}=0.05$ (based on the maximum value of the coefficient of variation of endothelial vasodilation); and the maximum error of the estimate taken as the maximum variability in arterial diameter measures by two observers $(0.02 \%)$ [41], it was estimated that $\mathrm{n}_{\mathrm{p} 1}=26.1 \cong$ 26 hypertensive individuals. Thus, in the estimate of $n$, the approximation used considered $\mathrm{n}_{\mathrm{p} 1}=26, \mathrm{gl}=23$, and $t_{0.05 ; 23}=2.069$. The $n_{p 1}=26.8 \cong 27$. The estimate of the sample size for the study was $n=80.3 \cong 81$ hypertensive individuals who will be randomly assigned to the three training interventions.

\section{Randomization procedure}

A randomization for the proposed interventions will be generated by a computer program (www.randomization.org) including the distribution coded at a 1:1 ratio. The random assignment of subjects to training intervention groups will be into three blocks of 27. Subjects will be drawn up to 27 in each intervention group: aerobic training (AT), resistance training (RT), and combined training ( $\mathrm{CT}$, resistance and aerobic). All subjects will be blinded to intervention allocation and will have access to this information only after the baseline assessment. All evaluators of the study subjects will be also blinded to intervention allocation.

\section{Baseline assessment of subjects}

After recruitment, the subjects will undergo baseline assessment to collect information on their main characteristics before intervention. A descriptive exploratory questionnaire will be administered to collect information on i) demographic and socioeconomic variables (gender, age, socioeconomic status, education, skin color and marital status); ii) behavioral variables (physical activity measured by the International Physical Activity Questionnaire (www.ipaq.ki.se), smoking status, and alcohol consumption); iii) anthropometric variables (body weight, height, and waist circumference); iv) clinical variables (BP and use of antihypertensive medication); and v) quality of life assessed by the Medical Outcomes Study 36-Item Short Form Health Survey (SF-36) [42]. Eligible individuals who are willing to participate will be instructed to fast for $8 \mathrm{~h}$ and come for a scheduled second visit at the study site. In this visit, subjects will have blood samples collected for blood testing, in addition to the assessment of FMD of the brachial artery and ambulatory blood pressure monitoring (ABPM) cuff placement. A snack will be offered at the end of this visit. In the third visit, the ABPM cuff will be removed and subjects will undergo physical fitness tests $\left(\mathrm{VO}_{2} \mathrm{max}\right)$. In the fourth visit, 1-RM testing will be conducted. Subjects who did not show up for the scheduled visits will be contacted again. All blood samples will be collected by a nurse technician. All assessment procedures will be supervised by the study investigators and ICFUC medical staff.

\section{Assessments}

\section{Blood collection}

Blood collection and testing will be performed at the ICFUC. Subjects' blood will be collected after a fast of 8 h. The blood sample will be tested for biochemical screening (lipid profile, glucose, glycated hemoglobin, and creatinine), number of EPCs and number of circulating endothelial microparticles. In addition, blood rheology will be assessed for potential changes in the sample studied including increased blood viscosity, reduced red blood cell (RBC) deformability, increased $\mathrm{RBC}$ aggregation, fibrinogen levels, and erythrocyte sedimentation rate (ESR).

\section{Progenitor cell and endothelial progenitor cell count}

A 15-ml blood sample for the EPCs will be collected in a Sodium Heparin Vacutainer ${ }^{\mathrm{TM}}$ tube. Peripheral blood mononuclear cells (PBMC) will be isolated using Ficoll-Paque (GE Heathcare Life Sciences, Uppsala, Sweden). Progenitor cells (PCs) will be defined as CD34+/CD45dim, and EPCs as CD34+/KDR+/CD45dim. Briefly, blood samples will be diluted once with phosphate buffered saline (PBS) and layered onto Ficoll-Paque in 15-ml conical tubes (BD 
Instituto de Cardiologia / Fundação Universitária de Cardiologia
Individuals with HAS (n=81)

Excluded

Not meeting inclusion criteria

Declined to participate

Other reasons

Questionnaire: demographic, socioeconomic data, gender, age, education, skin color, marital status, smoking status, alcohol consumption, level of physical activity (IPAQ), length of time with diagnosis of hypertension, anti-hypertensive medications currently used and quality of life (SF36). Anthropometric data (weight, height and waist circumference). Measurement of blood pressure clinical and ambulatory monitoring (AMBP). Endothelial function (flow-mediated dilation - FMD). Echocardiography, Functional capacity (V02max) and One-repetition maximum strength assessment (1-RM). Laboratory analyses (blood collection: number of circulating endothelial progenitor cells, number of circulating endothelial microparticles, lipid profile, glucose, glycated hemoglobin and creatinine).

Randomized 1:1

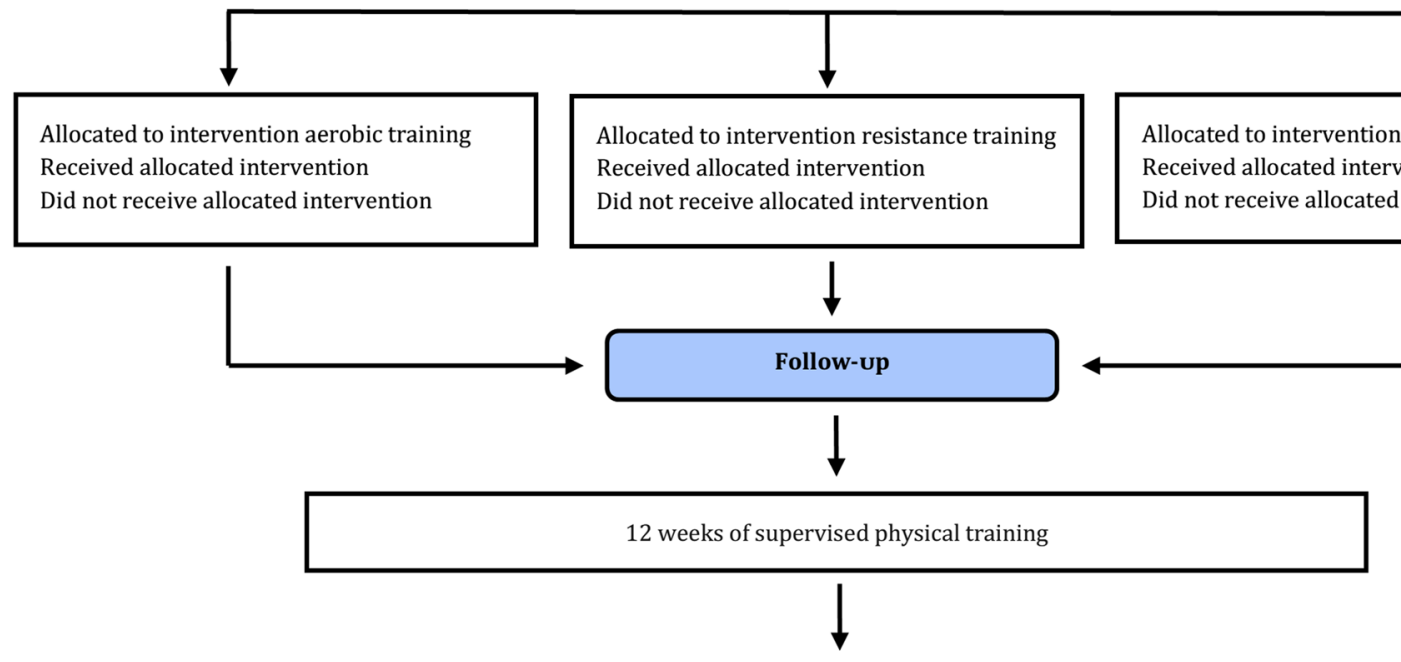

Questionnaire: quality of life (SF36) and Physical Activity Questionnaire (IPAQ). Anthropometric data (weight, height and waist circumference). Measurement of blood pressure clinical and ambulatory monitoring (AMBP). Endothelial function (flow-mediated dilation FMD). Echocardiography, Functional capacity (VO2max) and One-repetition maximum strength assessment (1-RM). Laboratory analyses (blood collection: number of circulating endothelial progenitor cells, number of circulating endothelial microparticles, lipid profile, glucose, glycated hemoglobin and creatinine).

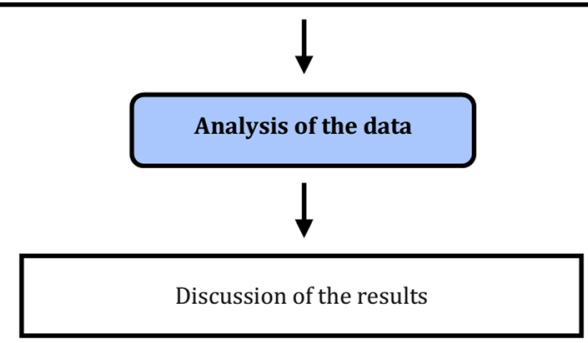

Fig. 1 Study design. Flow chart of how the clinical trial will be conducted

Biosciences, San Jose, CA, USA). Each tube will be centrifuged at $400 \mathrm{xg}$ for $30 \mathrm{~min}$ (Eppendorf-5810, Hamburg, Germany), and the PBMCs at the interface will be collected. Cells will be washed once with RPMI-
1640 medium (Gibco ${ }^{\mathrm{Tm}}$, Vancouver, Canada); stained with $5 \mu \mathrm{l}$ of antihuman-CD45 FITC, $5 \mu \mathrm{l}$ of antihuman-CD34 PE (clone 6G12), and 8 ul of antihuman-KDR-Alexa Fluor 647 (BD Biosciences, 
Table 3 Inclusion and exclusion criteria for the study

\begin{tabular}{ll}
\hline Inclusion criteria & Exclusion criteria \\
\hline - Males and females aged 18 to 70 years & - Currently engaging in any type of systematic physical activity \\
- Diagnosed with SAH & Blood pressure hyper-reactivity in the clinical assessment (SBP $>220 \mathrm{mmHg}$ \\
- Signed a free informed consent form & and/or increase in DBP $>15 \mathrm{mmHg}$ ) \\
- Considered insufficiently active (IPAQ) & - Ongoing infectious diseases \\
- Non-active smokers & - Heart failass II or III (BMI) \\
& renal failure; and malignant disease with life expectancy $<2$ years \\
& - Orthopedic impairments or any physical or mental limitations that prevent physical exercises \\
& - After the training intervention, individuals who attended $<85 \%$ or missed $>2$ consecutive \\
& training sessions will be excluded from the sample. Subjects will be encouraged to complete \\
& any missed session at the end of training by performing additional sessions.
\end{tabular}

SAH, systemic arterial hypertension; IPAQ, International Physical Activity Questionnaire; SBP, systolic blood pressure; DBP, diastolic blood pressure; BMI, body mass index

San Jose CA, USA); and incubated in the dark for $30 \mathrm{~min}$, followed by the addition of $500 \mu \mathrm{l}$ of PBS until resuspension and acquisition in a flow cytometer (FACSCalibur, CellQuest software, BD Biosciences, San Diego, CA, USA). The total number of events recorded on the mononuclear cells gate was 200,000. The percentage of CD34+ cells was calculated based on the measured number of leukocytes (CD45+ cells) using the ISHAGE (International Society for Hematotherapy and Graft Engineering) gating strategy [43].

\section{Circulating endothelial microparticles count}

A 5-ml blood sample for circulating endothelial microparticles will be collected in a Citrate Vacutainer ${ }^{\text {ru }}$ tube. These samples will be analyzed for CD31+/CD41- and CD144+. Initially, the blood will be rendered to separate the platelet-rich plasma and the platelet-poor plasma. All blood samples will be subjected to a two-step protocol centrifugation (860 $\mathrm{xg}$ for $15 \mathrm{~min}$ at $4{ }^{\circ} \mathrm{C}$, followed by $1700 \mathrm{xg}$ for $5 \mathrm{~min}$ at $20^{\circ} \mathrm{C}$ ) before being stored at $-80{ }^{\circ} \mathrm{C}$. Phenotype analysis of the endothelial microparticles will be subsequently performed on samples thawed using a flow cytometer Fluorescence Activated Cell Analyser (FACScanto II da BD Biosciences, San Jose, CA, USA) and the results analyzed with the BD FACS Diva software (BD). For phenotyping of the endothelial microparticles, the following antibodies will be used: anti$\mathrm{CD} 31+\mathrm{PE}$, anti-CD41+ PC7, and anti-CD144+ PE. Endothelial microparticles will be defined as elements with size $>0.1$ and $<1.0 \mu \mathrm{m}$ and showing surface markers CD31+/CD41- and CD144+ [44].

\section{Assessment of flow-mediated dilation (FMD)}

Endothelial function will be measured noninvasively by using brachial artery ultrasound (EnVisor series, Philips Ultrasound, Bothell, WA, USA). This assessment will be performed with a 7 to $12 \mathrm{MHz}$ linear transducer in a heated room at 21 to $24{ }^{\circ} \mathrm{C}$ at ICFUC. A software program will be used for two-dimensional color-Doppler imaging acquisition with a simultaneously recorded electrocardiogram (ECG). Image data will be recorded on a
DVD. To minimize operational errors, the subject's arm, and the ultrasound transducer will be positioned and maintained in the same position during the procedure. Baseline images will be recorded. A cuff will be placed around the forearm and inflated to $50 \mathrm{mmHg}$ above systolic pressure for at least $5 \mathrm{~min}$ and then removed. Longitudinal ultrasound images of the brachial artery walls will be acquired to assess endothelium-dependent vasodilation. The expected coefficient of variation between the images will be 1.8 to $5.0 \%$. Flow-dependent vasodilation responses will be expressed as the percentage change in the brachial diameter [36].

\section{Echocardiography}

Echocardiography is a noninvasive imaging approach that uses ultrasound to assess the structures and functioning of the heart; it measures the chamber size and mobility of the walls, valve structures, ejection fraction, diastolic dysfunction parameters, and the direction and speed of blood flowing through the heart chambers. Medical personnel at ICFUC accredited by the Brazilian Society of Echocardiography and blinded to intervention allocation will perform transthoracic echocardiograms with image acquisition in second-harmonic generation with the use of ACUSON SC2000 equipment and a 3 to $12 \mathrm{MHz}$ transducer (Siemens). This data will be digitally stored for further analysis by more experienced evaluators.

\section{Blood pressure}

Two different approaches will be used to evaluate the BP levels: clinical assessment and ambulatory blood pressure monitoring (AMBP). The clinical assessment will consist of acute and subacute BP measurements as a way to evaluate exercise responses. Measurements will be taken with the subject in a sitting position using a semi-automatic sphygmomanometer (Omron 705CP). $\mathrm{BP}$ levels will be measured in both arms in the pre-study assessments, and the arm with highest values will be used for measurements in the study. Subacute clinical assessments will be conducted at the following time 
points: before the beginning of each training session (pre-exercise), immediately after exercise (early postexercise), and $20 \mathrm{~min}$ after the end of each session (late post-exercise). ABPM will be performed in all study groups before the first exercise session and at the completion of the entire training intervention. Blood pressure measurements will be obtained from an oscillometric Dina-map ${ }^{\text {tw }}$ device. Both assessments will follow the VI Brazilian National Guidelines in Cardiology [40].

\section{Functional capacity}

$\mathrm{VO}_{2}$ max will be obtained from a cardiopulmonary exercise test using a cycle ergometer and 12-lead ECG monitoring supervised by a cardiologist. Gas exchange measurements will be taken with the use of an ergo spirometer (VO2000 model, Inbramed, Porto Alegre, Brazil). This device collects exhaled gas samples and can store data acquired with each breath (breath-by-breath). Heart rate will be monitored with a frequency meter (Polar S610 model) as follows: online heart rate readings, determination of maximum heart rate at each exercise stage, and stopwatch with partial times. The maximal exercise test will be scheduled at least $48 \mathrm{~h}$ in advance. Upon participant arrival at the study site, BP levels will be measured according to the study protocol. Subjects will be asked to sit on a chair, and a facemask (or nozzle) and a frequency meter will be attached. Resting $\mathrm{VO}_{2}$ and $\mathrm{VCO}_{2}$ measurements will be taken, and the test will be started only when the respiratory exchange ratio (RER) is lower than 0.95 . The test will be stopped when the subjects are exhausted and signal that they can no longer turn the pedals [45].

\section{One-repetition maximum strength (1-RM) assessment}

The one-repetition maximum strength test (1-RM) will be used to measure the maximum strength. Subjects will warm up on a cycle ergometer for $5 \mathrm{~min}$. They will then be instructed to perform the maximum number of repetitions with a given load until they can perform only one lift of a load in up to five attempts to achieve the maximum load. A rest period of 3 to $5 \mathrm{~min}$ will be provided between each attempt, so rest intervals are of sufficient length to allow the restoration of energy reserves [46]. The same procedure will be followed for all types of strength exercises proposed in the study (leg press, bench press, knee extension, biceps curl, knee bend, and low row). The speed of movements will be controlled with a metronome in both intervention protocols. Exercises will be performed at a pace of 2 seconds for both concentric and eccentric phases. This test will take place at three time points: during the first 2 weeks ( $60 \%$ of 1 $\mathrm{RM}$ ); during the intermediate weeks (70\% of 1-RM); and at the end of week 8 ( $80 \%$ of $1-\mathrm{RM})$ to maintain exercise at an appropriate intensity throughout the protocol.

\section{Intervention protocols}

The study intervention will comprise 12 weeks of exercise sessions, lasting on average $50 \mathrm{~min}$, three times a week. Exercise sessions will include a warm-up period of 5 to $10 \mathrm{~min}$ at the beginning, resistance or combined aerobic exercises for $40 \mathrm{~min}$, and a cool down/relaxation period.

AT will be performed on a cycle ergometer for the entire intervention. Subjects will be monitored with heart rate monitors (Table 4).

RT will include six types of exercises that alternate between large and small muscle groups (leg press, bench press, knee extension, biceps curl, knee bend, and low row) for the entire training intervention (Table 5).

CT will consist of resistance and aerobic exercises combined in one session performed over a 40-min period set as in the other two protocols, so that training volume is similar across all intervention groups for the entire intervention (Table 6).

A basic training principle is the progression of exercise intensity, duration, or frequency. Progression of exercise in the study intervention will be through gradual exertion increase for the protocols [46]. Borg's rating scale of perceived exertion ( 6 to 20 point scale) will be used to help control the training intensities [47]. All subjects will be allowed an initial adjustment period. Those with resting BP levels higher than $160 \mathrm{mmHg}$ (SBP) and/or $105 \mathrm{mmHg}$ (DBP) before cardiopulmonary testing, 1$\mathrm{RM}$, or an exercise session (AT, RT and CT) will not be allowed to participate in any activities [40]. Those experiencing BP higher than the recommended level on a second occasion will be referred to the study cardiologist for evaluation. The cardiologist will determine whether the subject can continue participating in the study.

Subjects diagnosed with SAH and diabetes mellitus type 2 will have their blood glucose checked (Optium Xceed, Abbott Diabetes Care, Inc., Alameda, CA, USA) in addition to BP measurements before cardiopulmonary exercise testing, 1-RM or an exercise session (AT, RT, and $\mathrm{CT}$ ) and every $15 \mathrm{~min}$ throughout exercise sessions. If the blood glucose levels are lower than $100 \mathrm{mg} / \mathrm{dL}$

Table 4 Intensity and duration of aerobic training on a stationary bike during a 12-week intervention

\begin{tabular}{llll}
\hline & Phase I & Phase II & Phase III \\
\hline Intensity & 50 to $65 \%$ & 55 to $70 \%$ & 60 to $75 \%$ \\
& HRR & HRR & HRR \\
Session duration & 40 min & 40 min & 40 min \\
$\begin{array}{l}\text { Exercise duration } \\
\text { (weeks) }\end{array}$ & 4 & 4 & 4 \\
\hline
\end{tabular}

HRR, heart rate reserve 
Table 5 Intensity, number of sets, repetitions, rest period between sets, and session duration of resistance training during a 12-week intervention

\begin{tabular}{llll}
\hline & Phase I & Phase II & Phase III \\
\hline Intensity & 60 \% 1-RM & $70 \%$ 1-RM & $80 \%$ 1-RM \\
Sets & 4 & 4 & 4 \\
Repetitions & 10 to 12 & 8 to 10 & 6 to 8 \\
Rest period between sets & $60 \mathrm{~s}$ & $60 \mathrm{~s}$ & $90 \mathrm{~s}$ \\
Session duration & $40 \mathrm{~min}$ & $40 \mathrm{~min}$ & $40 \mathrm{~min}$ \\
Exercise duration (weeks) & 4 & 4 & 4 \\
\hline
\end{tabular}

1-RM, one-repetition maximum strength test

during cardiopulmonary exercise testing, 1-RM, or exercise sessions (AT, RT and CT), subjects will receive 30 to 45 g glucose gel (Gli-Instan, Lightsweet ${ }^{\mathrm{TM}}$ ) to maintain levels above $120 \mathrm{mg} / \mathrm{dL}$, and their blood glucose will be checked again 15 min later. Those with blood glucose higher than $250 \mathrm{mg} / \mathrm{dL}$ will have their urine tested for the presence of ketones (ComboStik ${ }^{\mathrm{TM}}$, Gyung-Nam, Korea), and they will be allowed to resume exercise only if test results are negative. Subjects with blood glucose lower than $100 \mathrm{mg} / \mathrm{dL}$ during exercise sessions will have to discontinue exercising and be offered a snack. Their blood glucose will be tested again 15 min later, and they will be allowed to resume exercise only if their test results are acceptable [48].

\section{Statistical procedures}

For data comparison between pre-exercise and postexercise and across groups, nonparametric (Spearman's correlation $(\rho)$, chi-square test $\left(\chi^{2}\right)$, and Mann-Whitney $\mathrm{U}$ test), and parametric tests (t-test, analysis of variance (ANOVA), multivariate analysis of variance (MANOVA), multivariate linear regression, and canonical discriminant

Table 6 Intensity, number of sets, repetitions, rest period between sets, and session duration of concurrent training during a 12-week intervention

\begin{tabular}{|c|c|c|c|}
\hline & Phase I & Phase II & Phase III \\
\hline \multicolumn{4}{|l|}{ Resistance training } \\
\hline Intensity & $60 \% 1-R M$ & $70 \% 1-R M$ & $80 \% 1-R M$ \\
\hline Sets & 2 & 2 & 2 \\
\hline Repetitions & 10 to 12 & 8 to 10 & 6 to 8 \\
\hline $\begin{array}{l}\text { Rest period } \\
\text { between sets }\end{array}$ & $60 \mathrm{~s}$ & $60 \mathrm{~s}$ & $90 \mathrm{~s}$ \\
\hline Session duration & $20 \mathrm{~min}$ & $20 \mathrm{~min}$ & $20 \mathrm{~min}$ \\
\hline \multicolumn{4}{|l|}{ Aerobic training } \\
\hline Intensity & 50 to $65 \%$ HRR & 55 to $70 \%$ HRR & 60 to $75 \%$ HRR \\
\hline Session duration & $20 \mathrm{~min}$ & $20 \mathrm{~min}$ & $20 \mathrm{~min}$ \\
\hline $\begin{array}{l}\text { Exercise duration } \\
\text { (weeks) }\end{array}$ & 4 & 4 & 4 \\
\hline
\end{tabular}

1-RM, one-repetition maximum strength test; HRR, heart rate reserve analysis) will be used depending on the variable studied, as well as post hoc tests (Duncan and Waller-Duncan ANOVA and MANOVA) [49]. The significance level will be set at 0.05 . All statistical analysis will be performed using SPSS version 22.0.

\section{Ethical issues}

The study protocol followed the principles of the Declaration of Helsinki and was approved by the research ethics committee (Protocol 925.406 by Instituto de Cardiologia do RS/Fundação Universitária de Cardiologia - Brazil, dated 22 December 2014 and signed by Dr. Leonardo Martins Pires). Furthermore, all subjects will read and give their informed consent for participation in the research study. All information will be confidential, subjects' names will be kept confidential, and data will be collected for academic purposes only according to Resolution CNS N1466/12 [50]. If subjects in the RT and CT groups do not show any improvements of endothelial function (primary endpoint) or BP levels compared to those in the AT group, they will be offered the opportunity to practice the AT protocol after completion of the study to ensure equal benefits for all subjects.

\section{Discussion}

The Study of Endothelial Function Response to Exercise Training (SEFRET) is a single-site study that will be conducted in the city of Porto Alegre, Brazil. The study will be conducted in accordance with the principles of Good Clinical Practice and all requirements established by ICFUC relevant bodies and collaborators.

The study results are expected to provide evidence of cardiovascular protective effects of different types of exercise training by modulating endothelial function in individuals with SAH. Knowing the magnitude of improvement of endothelium-dependent vasodilation by different types of exercise training can provide scientific evidence to the prescription of exercise programs for vascular protection targeted to hypertensive individuals. An adequate exercise program can lead to significant changes in cardiovascular function and promote health benefits and BP control, thus reducing adverse cardiovascular outcomes.

\section{Trial status report \\ Recruiting.}

\footnotetext{
Abbreviations

ABPM: ambulatory blood pressure monitoring; AT: aerobic training; BMI: body mass index; BP: pressure blood; CT: combined training; DBP: diastolic blood pressure; ECG: electrocardiogram; eNOS: endothelial nitric oxide synthase; ESR: erythrocyte sedimentation rate; FMD: flow-mediated dilation; FUC: Fundação Universitária de Cardiologia; HDL: high-density cholesterol; HRR: heart rate reserve; IC: Instituto de Cardiologia; IPAQ: International Physical Activity Questionnaire; LDL: low-density cholesterol; NO: nitric oxide; PBMN: Peripheral blood mononuclear cells; PBS: phosphate buffered saline; PCs: Progenitor cells; RBC: red blood cell; RT: resistance training;
} 
SAH: systemic arterial hypertension; SBP: systolic blood pressure; WHO: World Health Organization; 1-RM: one repetition maximum..

\section{Competing interests}

The authors declare that they have no competing interests.

\section{Authors' contributions}

MP and AML conceived and designed the research study and were involved with the preparation, organization, and registration of the study and obtaining approval from the local research ethics committee. MP, AML and IC will participate in the selection, recruitment and assessment of study subjects. MP will be the principal investigator. GW and AC will be members of the exercise training team. GW, MMM, and IC will also contribute to the analysis and interpretation of the data. All authors will participate in drafting and revising the manuscript for intellectual content and will review and approve the final manuscript before submission.

\section{Acknowledgments}

The authors thank Carla Finger for English assistance and Dr. Walter Nisa Castro Neto for statistical expertise.

The project will be funded by FAPPIC (Fundo de Apoio à Pesquisa do Instituto de Cardiologia / Fundação Universitária de Cardiologia).

\section{Author details}

${ }^{1}$ Laboratório de Investigação Clínica, Instituto de Cardiologia / Fundação Universitária de Cardiologia - ICFUC, Av. Princesa Isabel, 395. Bairro Santana, 90620001 Porto Alegre, RS, Brazil. ²Universidade Luterana do Brasil - ULBRA, Torres, Rio Grande do Sul, Brazil. ${ }^{3}$ Faculdade Sogipa de Educação Física, Porto Alegre, Rio Grande do Sul, Brazil.

\section{Received: 9 September 2015 Accepted: 3 February 2016} Published online: 13 February 2016

\section{References}

1. Paffenbarger Jr RS, Jung DL, Leung RW, Hyde RT. Physical activity and hypertension: an epidemiological view. Ann Med. 1991;23:319-27.

2. Fagard $\mathrm{RH}$. Physical activity, physical fitness and the incidence of hypertension. J Hypertens. 2005;23(2):265-7.

3. Obesity: preventing and managing the global epidemic: report of a $\mathrm{WHO}$ Consultation on Obesity, Geneva, 3-5 June 1997. https://extranet.who.int/ iris/restricted/handle/10665/63854?mode=full. Accessed 25 Nov 2014.

4. de Simone G, Devereux RB, Chinali M, Roman MJ, Best LG, Welty TK, et al. Strong Heart Study. Risk Factors for Arterial Hypertension in Adults With Initial Optimal Blood Pressure. Hypertension. 2006:47(2):162-7.

5. Seligman BG, Polanczyk CA, Santos AS, Foppa M, Junges M, Bonzanini L, et al. Intensive practical lifestyle intervention improves endothelial function in metabolic syndrome independent of weight loss: a randomized controlled trial. Metabolism. 2011;60:1736-40.

6. Hatzis G, Tousoulis D, Papageorgiou N, Bouras G, Oikonomou E, Miliou A, et al. Combined effects of smoking and interleukin- 6 and C-reactive protein genetic variants on endothelial function, inflammation, thrombosis and incidence of coronary artery disease. Int J Cardiol. 2014;176:254-7.

7. Fahs CA, Smith DL, Horn GP, Agiovlasitis S, Rossow LM, Echols G, et al. Impact of excess body weight on arterial structure, function, and blood pressure in firefighters. Am J Cardiol. 2009;104:1441-5.

8. Belin de Chantemele EJ, Stepp DW. Influence of obesity and metabolic dysfunction on the endothelial control in the coronary circulation. J Mol Cell Cardiol. 2012; 52840-7.

9. Nosova EV, Yen P, Chong KC, Alley HF, Stock EO, Quinn A, et al. Short-term physical inactivity impairs vascular function. J Surg Res. 2014;190:672-82.

10. Kubisz P, Stančiaková L, Staško J, Galajda P, Mokáň M. Endothelial and platelet markers in diabetes mellitus type 2. World J Diabetes. 2015;6:423-31.

11. Soloviev MA, Kulakova NV, Semiglazova TA, Borodulina EV, Udut W. Correction of endothelial dysfunction in patients with arterial hypertension. Bull Exp Biol Med. 2011:151:183-85.

12. Anderson TJ, Uehata A, Gerhard MD, Meredith IT, Knab S, Delagrange D, et al. Close relation of endothelial function in the human coronary and peripheral circulations. J Am Coll Cardiol. 1995;26:1235-41.
13. Tomiyama $\mathrm{H}$, Yamashina A. Non-invasive vascular function tests: their pathophysiological background and clinical application. Circ J. 2010;74:24-33.

14. Félétou M, Vanhoutte PM. Endothelial dysfunction: a multifaceted disorder (The Wiggers Award Lecture). Am J Physiol Heart Circ Physiol. 2006:291:H985-1002.

15. Jenkins NT, Padilla J, Boyle LJ, Credeur DP, Laughlin MH, Fadel PJ. Disturbed blood flow acutely induces activation and apoptosis of the human vascular endothelium. Hypertension. 2013;61:615-21.

16. Kalka C, Masuda H, Takahashi T, Kalka-Moll WM, Silver M, Kearney M, et al. Transplantation of ex vivo expanded endothelial progenitor cells for therapeutic neovascularization. Proc Natl Acad Sci U S A. 2000;97:3422-27.

17. Vasa M, Fichtlscherer S, Aicher A, Adler K, Urbich C, Martin H, et al. Number and migratory activity of circulating endothelial progenitor cells inversely correlate with risk factors for coronary artery disease. Circ Res. 2001:89:E1-7.

18. Hill JM, Zalos G, Halcox JP, Schenke WH, Waclawiw MA, Quyyumi AA, et al. Circulating endothelial progenitor cells, vascular function, and cardiovascular risk. N Engl J Med. 2003;348:593-600.

19. Werner N, Kosiol S, Schiegl T, Ahlers P, Walenta K, Link A, et al. Circulating endothelial progenitor cells and cardiovascular outcomes. N Engl J Med. 2005:353:999-1007.

20. Liu X, Zhang GX, Zhang XY, Xia WH, Yang Z, Su C, et al. Lacidipine improves endothelial repair capacity of endothelial progenitor cells from patients with essential hypertension. Int J Cardiol. 2013;168:3317-26.

21. Puls M, Schroeter MR, Steier J, Stijohann L, Hasenfuss G, Konstantinides S, et al. Effect of smoking cessation on the number and adhesive properties of early outgrowth endothelial progenitor cells. Int J Cardiol. 2011;152:61-9.

22. Devaraj S, Jialal I. Dysfunctional endothelial progenitor cells in metabolic syndrome. Exp Diabetes Res. 2012;2012:585018.

23. António N, Fernandes R, Soares A, Soares F, Lopes A, Carvalheiro T, et al. Reduced levels of circulating endothelial progenitor cells in acute myocardial infarction patients with diabetes or pre-diabetes: accompanying the glycemic continuum. Cardiovasc Diabetol. 2014;13:101.

24. Zerbini G, Lorenzi M, Palini A. Tumor angiogenesis. N Engl J Med. 2008;359: 763. author reply 764 .

25. James PA, Oparil S, Carter BL, Cushman WC, Dennison-Himmelfarb C, Handler J, et al. 2014 evidence-based guideline for the management of high blood pressure in adults: report from the panel members appointed to the Eighth Joint National Committee (JNC 8). JAMA. 2014;311:507-20.

26. Ficker ES, Maranhão RC, Chacra AP, Neves VC, Negrão CE, Martins VC, et al. Exercise training accelerates the removal from plasma of LDL-like nanoemulsion in moderately hypercholesterolemic subjects. Atherosclerosis. 2010:212:230-6.

27. Silva JF, Rocha NG, Nóbrega AC. Mobilization of endothelial progenitor cells with exercise in healthy individuals: a systematic review. Arq Bras Cardiol. 2012;98:182-91.

28. Volaklis KA, Tokmakidis SP, Halle M. Acute and chronic effects of exercise on circulating endothelial progenitor cells in healthy and diseased patients. Clin Res Cardiol. 2013;102:249-57.

29. Frank P, Andersson E, Pontén M, Ekblom B, Ekblom M, Sahlin K. Strength training improves muscle aerobic capacity and glucose tolerance in elderly. Scand J Med Sci Sports. 2015. doi:10.1111/sms.12537

30. De Nigris V, Pujadas G, La Sala L, Testa R, Genovese S, Ceriello A. Short-term high glucose exposure impairs insulin signaling in endothelial cells. Cardiovasc Diabetol. 2015;14:114.

31. Shi L, Morrison JA, Wiecha J, Horton M, Hayman LL. Healthylifestyle factors associated with reduced cardiometabolic risk. Br J Nutr. 2011;105:747-54.

32. Montero D, Walther G, Benamo E, Perez-Martin A, Vinet A. Effects of exercise training on arterial function in type 2 diabetes mellitus: a systematic review and meta-analysis. Sports Med. 2013:43:1191-9.

33. Vuckovic KM, Piano MR, Phillips SA. Effects of Exercise Interventions on Peripheral Vascular Endothelial Vasoreactivity in Patients with Heart Failure with Reduced Ejection Fraction. Heart Lung Circ. 2013;22:328-40.

34. Cornelissen VA, Smart NA. Exercise training for blood pressure: a systematic review and meta-analysis. J Am Heart Assoc. 2013;2:e004473.

35. Ribeiro AS, Tomeleri CM, Souza MF, Pina FL, Schoenfeld BJ, Nascimento MA Venturini D, Barbosa DS, Cyrino ES. Effect of resistance training on C-reactive protein, blood glucose and lipid profile in older women with differing levels of RT experience. Age (Dordr). 2015;37:109.

36. Corretti MC, Anderson TJ, Benjamin EJ, Celermajer D, Charbonneau F, Creager MA, et al. Guidelines for the ultrasound assessment of 
endothelial-dependent flow-mediated vasodilation of the brachial artery: a report of the International Brachial Artery Reactivity Task Force. J Am Coll Cardiol. 2002;39:257-65.

37. Montezano AC, Dulak-Lis M, Tsiropoulou S, Harvey A, Briones AM, Touyz RM Oxidative stress and human hypertension: vascular mechanisms, biomarkers, and novel therapies. Can J Cardiol. 2015;31:631-41.

38. Schmidt-Lucke C, Fichtlscherer S, Aicher A, Tschöpe C, Schultheiss HP, Zeiher AM, et al. Quantification of circulating endothelial progenitor cells using the modified ISHAGE protocol. PLoS One. 2010;5:e13790.

39. Amabile N, Cheng S, Renard JM, Larson MG, Ghorbani A, McCabe E, et al. Association of circulating endothelial microparticles with cardiometabolic risk factors in the Framingham Heart Study. Eur Heart J. 2014;35:2972-79.

40. Sociedade Brasileira de Cardiologia, Sociedade Brasileira de Hipertensão, Sociedade Brasileira de Nefrologia. VI Brazilian Guidelines on Hypertension. Arq Bras Cardiol. 2010;95 Suppl 1:1-51.

41. Sorensen KE, Celermajer DS, Spiegelhalter DJ, Georgakopoulos D, Robinson J, Thomas $\mathrm{O}$, et al. Non-invasive measurement of human endothelium dependent arterial responses: accuracy and reproducibility. Br Heart J. 1995; 74:247-53.

42. Ciconelli RM, Soarez PC, Kowalski CC, Ferraz MB. The Brazilian Portuguese version ofthe Work Productivity and Activity Impairment: General Health (WPAl-GH) Questionnaire. São Paulo Med J. 2006;124:325-32.

43. Waclawovsky G, Umpierre D, Figueira FR, de Lima ES, Alegretti AP, Schneider L, et al. Exercise on Progenitor Cells in Healthy Subjects and Patients with Type 1 Diabetes. Med Sci Sports Exerc. 2015 [Epub ahead of print].

44. Schiro A, Wilkinson FL, Weston R, Smyth JV, Serracino-Inglott F, Alexander MY. Elevated levels of endothelial-derived microparticles, and serum CXCL9 and SCGF- $\beta$ are associated with unstable asymptomatic carotid plaques. Sci Rep. 2015;5:16658.

45. Sociedade Brasileira de Cardiologia. III Guidelines of Sociedade Brasileira de Cardiologia on the exercise test. Arq Bras Cardiol. 2010;95(5 Suppl 1):1-26.

46. Baechle T, Earle R. Essentials of Strength Training and Conditioning. 3rd ed. Champaigne: Human Kinetics; 2008.

47. Borg G. Psychophysical basis of perceived exertion. Med Sci Sports Exerc. 1982;14:377-81.

48. Colberg SR. Exercise and Diabetes: A Clinician's Guide to Prescribing Physical Activity. Alexandria: American Diabetes Association; 2013.

49. Zar JH. Biostatistical Analysis. 4th ed. Prentice Hall: Upper Saddle River; 1999.

50. Conselho Nacional de Saúde (Brasil). Resolução n 466, de 12 de dezembro de 2012. Braślia, 2012 [citado 2014 Mar 11]. http://www.conselho.saude.gov. br/web_comissoes/conep/index.html. Accessed 4 January 2014.

\section{Submit your next manuscript to BioMed Central and we will help you at every step:}

- We accept pre-submission inquiries

- Our selector tool helps you to find the most relevant journal

- We provide round the clock customer support

- Convenient online submission

- Thorough peer review

- Inclusion in PubMed and all major indexing services

- Maximum visibility for your research

Submit your manuscript at www.biomedcentral.com/submit

C Biomed Central 